\title{
Risks of switching to renewable energy sources
}

\author{
E.S. Romanova ${ }^{1}$, and A.A. Masalkova ${ }^{2}$ \\ ${ }^{1}$ The Russian Presidential Academy Of National Economy And Public Administration, \\ 119606, Moscow, Vernadskogo av., 84 \\ ${ }^{2}$ Gubkin Russian State University of Oil and Gas (National Research University), Leninsky \\ prospect 65, c.1, 119991 Moscow, Russia
}

\begin{abstract}
This research work is devoted to the issue of studying the key risks of switching to renewable energy sources. The relevance of the topic of work is determined by the fact that, according to climatologists [5], climate change, which has a negative impact on the environment, is caused by the emission of greenhouse gases such as carbon dioxide $\left(\mathrm{CO}_{2}\right)$. For this reason, measures to prevent or reduce greenhouse gas emissions are at the heart of the energy transition. International treaties such as the Kyoto Protocol and the Paris Agreement lay the foundations for global action to combat climate change and implement a fourth energy transition. The energy transition is characterized by a number of incentives and barriers. Despite the fact that there are many scenarios for the development of the global energy sector by 2050 , the expected transformations of the energy market lead to a significant redistribution of the ratio of the shares of hydrocarbon sources and renewable energy sources [16]. The trend towards fossil fuels is on the rise. These transformations in the market are determined not only by the climate agenda, but also by the concept of sustainable economic development.
\end{abstract}

\section{Introduction}

Renewable energy sources constitute the energy resources of constantly existing natural processes on the planet. An increase in the share of renewable energy sources in the energy balance serves the gradual replacement of hydrocarbon sources [4]. The main types of renewable sources are solar, wind, geothermal, hydropower, biomass, wave and tidal energy. Despite the belief that renewables are not competitive, some types of energy, in particular solar and wind energy, are actively replacing oil, natural gas and coal. The competitiveness of renewable energy is measured by the indicator of the levelized cost of electricity (LCOE), as well as the volume of investments [29]. The study revealed that since 2010 the volume of investments in renewable energy has exceeded investments in the exploration and production of hydrocarbon sources. With regard to comparing the levelized cost of electricity, it seems important to note that in 2019 the cost of generating electricity from natural gas exceeded the cost of generating electricity from wind power [27]. Of course, the principle of resource allocation is an important remark. Hydrocarbon-rich countries are experiencing difficulties in making the energy transition.

The transition of the world economy to low-carbon energy may not have positive, but also negative consequences. In order to avoid negative impact on the economy, the focus is 
on the issue of risk management of renewable energy. The main categories of risks inherent in renewable sources are political, economic, social, technological, environmental, and legal. The article provides an overview of the categories of risks. Each type of risk has its own characteristic that allows you to determine the likelihood of a risk event and potential consequences. Risk analysis allows governments and the private sector to assess barriers to renewable energy diffusion in a given country, and identify ways to mitigate or transfer risks. Renewable energy risks are interconnected, however, their degree of influence is determined by the socio-political and economic situation of each individual country.

The practical value of the work is the risk visualization map. As a result of our research, a new form of graphical presentation of risk data was created, focused on visualizing their internal structure, which qualitatively improves the risk management of renewable energy. This form can be used for an individualized assessment of country risks in the field of renewable energy sources.

The object of this research is the process of transition of the world economy to renewable energy sources (RES).

The subject of this research is to study the risks associated with the transition to renewable energy sources.

The main objective of the study is to identify the key risks of renewable energy sources and to develop a visually-oriented risk assessment method. To achieve this goal, we need to solve the following tasks:

1) Identify and address the main categories of renewable energy risks through PESTEL-analysis

\section{Identification and description of key risks of renewable energy sources}

In 2010, global investment in new renewable energy projects surpassed investment in new fossil fuel plants for the first time, thanks in large part to the attractiveness of renewables and policy measures to support less energy intensive industries. From 2010 to 2019, global investment in renewable energy continued to grow, totaling $\$ 2.6$ trillion. The largest share of investments was directed to increasing the capacity of solar and wind energy (Table 2) [8].

Table 2. Investments in renewable energy sources over the decade, 2010-2019

\begin{tabular}{|l|l|}
\hline Renewable energy sources & Investments, USD billion \\
\hline Wind energy & 1023 \\
\hline Solar energy & 1349 \\
\hline Biomass & 115.5 \\
\hline Hydropower & 42.7 \\
\hline Geothermal energy & 19.88 \\
\hline Biofuel & 27.3 \\
\hline Total & 2600 \\
\hline
\end{tabular}

Despite the increasing investment, the volume of renewable energy capacities grows in proportion to the growth of risks. For example, political and regulatory risks rise amid macroeconomic certainty, while weather-related risk becomes more pressing as investment in offshore wind farms increases. At the same time, access to risk management resources, including risk management methodology, availability of a database of industries, insurance guarantees in the field of renewable energy, remains limited. 
In view of the above, risk management in the renewable energy sector takes on a capital significance. It is necessary to note the most common features related to risk management and inherent in all types of renewable energy.

First, the greatest risk from a funding point of view is the early stages of renewable energy projects. The significant risks of this stage are financial, political and regulatory. In most cases, these risks are exacerbated by the impact of adverse macroeconomic trends in the market in many countries.

Second, the renewable energy sector faces significant obstacles in mitigating and redistributing risks. This can be explained by the lack of effective risk transfer mechanisms and limited access to information.

Third, diversification is the most effective tool for mitigating renewable energy risks. Operational risk reduction is achieved through the use of proven technologies in the development of renewable installations.

Fourth, in the field of renewable energy risk management, insurance is the most common mechanism for transferring risk to a third party. However, the use of alternative risk transfer mechanisms, such as weather derivatives, is also on the rise. The renewable energy sector also actively resorts to contracting with hardware suppliers to transfer operational risks.

Finally, in the renewable energy sector, the range of risk transfer modes is expanding. Over the next three years, an increase in access to hedging, weather derivatives, and insurance contracts is expected [15].

Risk identification is an important part of effective risk management in the renewable energy sector. As part of this work, key categories of risks were identified, a PESTELanalysis was carried out and a visually-oriented risk map was developed.

When determining the risks of developing renewable energy, risks should be divided into the following categories: political, economic, social, technological, environmental and legal.

Political risks play a significant role in the development of renewable energy sources. Political risk refers to the risk of investment losses in a particular country caused by changes in policy and political structure. Political risk refers to the actions of host governments that intentionally or unintentionally affect the return on investment costs.

1) Political risks can be divided into two categories - prospective and retrospective. Prospective political risks take into account the impact of an underdeveloped regulatory framework on the planning of new renewable projects, while retrospective political risks take into account the impact of existing renewable projects on financial stability due to changes in the political structure. The threat of retrospective political risks is higher, since the existing projects for the introduction and development of renewable energy capacities are more sensitive to political instability.

Tackling political risks has long been a major challenge in attracting global investment in renewable energy for two reasons. Firstly, it is difficult to give a quantitative assessment of political risk, and secondly, due to the subjectivity of the assessment of political risks, analysis and rating of certain types of political risk is no less difficult.

Overall, political risk deserves a lot of attention because the low price competitiveness of renewable energy means that these projects tend to depend on government support, which includes maintaining a premium price, priority access to the electric grid, assistance in attracting needed infrastructure investment, and government procurement. On the one hand, the viability of renewable projects can be severely limited by sudden policy changes. On the other hand, the policy itself acts as a tool to reduce the risks associated with prices and demand for electricity generated from renewable sources.

Considering the above, we can highlight the following political risks in the development of renewable energy. We have classified external political risks as interstate military conflicts or full-scale wars. According to the report [34], the transition to renewable energy sources can reduce the risk of large-scale wars, however, increase the number of small international 
conflicts. Only those countries with advanced technologies and intellectual property in the field of renewable energy will be the winners. Countries relying on increasing exports of fossil fuels may lose their former geopolitical weight.

Internal political risks included the level of corruption, political (cyber) terrorism, civil war, bureaucracy, instability of the authorities, impracticality of government obligations, ineffective government work, the risk of expropriation and excessive taxation.

Instability of the authorities, leading to more frequent reshuffles in the upper echelons of government, and low operational efficiency have the greatest impact on the delay in the development of renewable energy in developing countries and countries with economies in transition. The low efficiency of the government's work leads to difficulties in the implementation of subsidies. Accordingly, unstable energy policy, insufficient trust of the authorities in renewable energy sources become a barrier to the transition of the economy to the consumption of clean energy [37].

Developed countries introducing renewable energy capacities run the risk of expropriation and over-taxation. The risk of expropriation and over-taxation is also associated with the reluctance of many governments to abolish the import tax on equipment and spare parts needed for renewable energy installations. "Green Tariffs» refer to the political mechanism by which governments seek to subsidize renewable energy sources in order to increase their competitiveness alongside fossil fuels, but the reluctance and lack of strategic steps to apply these financial incentives lead to increased costs that impede development, operation and maintenance of the industry [32].

At the heart of bureaucratic risks are ineffective interaction between various authorities and the delay in the implementation of renewable projects, which unreasonably increases the development time and launch time. The increase in costs is also associated with the difficulties in obtaining permits. In general, the bureaucratic apparatus negatively affects the motivation of investors to finance projects in the field of renewable energy [7].

Political terrorism is acquiring the features of cyber terrorism, which undermines the efficiency of renewable energy facilities. New automated projects that require less human intervention can fuel the growth of cyberattacks [19].

Finally, there is a gap between the policy objectives set by governments and the actual results achieved in the implementation of energy policies. In most cases, there is no global realistic goal, which suggests the need to develop policies that meet legal and regulatory requirements that will allow the renewable energy industry to grow on its own. The impracticality of government commitments can affect investment in renewable energy and the operation of existing facilities [42].

2) The economic risks of the renewable energy sector are very diverse. We have grouped these risks into three categories: market, financial and strategic. Market risks include high volatility of revenues depending on the price of electricity, fluctuations in demand for electricity, competition of renewable sources with hydrocarbons in the market.

Undoubtedly, fossil fuels will have a significant impact on the energy balance in the future. Investments in the exploration and production of oil, coal and natural gas remain attractive. In most countries, fossil fuels are the cheapest and most readily available source of energy. The economic crisis, leading to falling prices for oil, coal or natural gas, also reduces the chance of renewable energy to take the place of fossil fuels in the energy mix of countries. Over time, competition between hydrocarbon and renewable sources intensifies, which contributes to even greater economic instability in the market [13].

Despite the fact that prices for electricity generated from renewable sources are rising, the risk of lower income remains relevant. The paradox of reducing the cost of generation based on renewable sources with an increase in the price of electricity can be explained by the fact that electricity production itself is $44 \%$. from cost, other main costs are the costs of transmission and distribution of electricity to the place of its use due to the fact that the 
capacity of renewable energy sources should be located far from consumers, where there is a lot of sun, wind, etc. [40]. However, electricity prices are subject to various economic factors, depending on, for example, reasons such as the volatile costs of generating companies, the volume of taxes and fees, which correlate with the level of revenue from the sale of electricity based on renewable sources. As such, income volatility can affect investor motivation.

When moving to renewable energy sources, it is also necessary to consider the demand for electricity. Undoubtedly, population growth will be positive, which will lead to an increase in energy demand. However, as part of the energy transition, there is a trend towards energy efficiency and digitalization, designed to contain the uncontrolled increase in energy demand. When considering the risk of volatile demand for electricity from renewable energy sources, it is also worth emphasizing that renewables are currently intermittent. The discontinuity of renewable energy indicates its inability to provide continuous electricity production without using batteries to smooth out rapid transitions. Due to the inability to generate electricity on an ongoing basis, the risk of changing demand is of capital importance.

The next category of economic risks in the renewable energy sector is financial risks.

One of them is related to government grants and subsidies. Government subsidies for conventional energy are much larger than subsidies for renewable energy sources. This puts renewable energy at a disadvantage. Subsidies provided by governments to generate electricity from hydrocarbon sources discourage the widespread use of low-carbon technologies. For example, coal companies in Australia and Indonesia still receive government subsidies for mining and exploration [13].

Another risk is the insufficient number of financial institutions. Renewable energy project developers face serious difficulties in obtaining financial assistance. There are a limited number of financial institutions and instruments to finance clean energy projects. This indicates that investments are considered risky, which demotivates investors [9].

We also pay attention to the large start-up capital. Renewable energy projects require large start-up capital investments. They also have a long payback period on investment costs. Tight lending measures and limited access to external financing exacerbate the risk of large start-up capital. In this regard, most projects are considered unviable. regime.

Among the financial risks are also changes in interest rates, operating costs, taxation

The strategic economic risks include reputational risk. Reputational risk is considered to be the possibility of a negative impact of public perception of the activities of energy companies to introduce and increase the share of renewable sources, the negative impact of advertising on the reputation of energy companies and investors. The consequences of reputational risk affect consumer attitudes and choices. In many ways, corporate reputation is built on how quickly and efficiently renewable energy companies can ensure transparency of operations, investments and projects. Successful companies attract new customers and build their reputation. However, this can have the opposite effect in the absence of a reputational risk management strategy.

3) Among the social risks, it is important to note social resistance to the introduction of renewable energy sources and health risks. Social resistance combines the level of public awareness and information barriers, the NIMBY syndrome, loss of other/alternative income, lack of experienced professionals.

Sustainable development is based on meeting human needs through the use of new technologies, appropriate policy strategies and regulatory instruments. The main problems of public awareness are insufficient information about the environmental and financial benefits of renewables, insufficient awareness of renewable energy technologies, and doubts about the financial feasibility of renewable energy projects [28]. 
The NIMBY syndrome refers to the resistance of local residents to changes in infrastructure in the area adjacent to the residents' home. According to the NIMBY syndrome, the population of most countries supports the development of renewable energy if construction work is not carried out in the area adjacent to their home. Renewable energy projects are criticized by individuals, political leaders, and public organizations. Public rejection arises due to changes in the landscape, environmental degradation, lack of interaction with the local population [24].

A major issue associated with renewable energy sources (especially solar and wind farms) is the need for a large area for energy production, equal to that which can be produced in a small coal-fired power plant. The energy transition requires the development of large-scale renewable power plants, but this requires vast areas of the countryside. Large areas of the countryside, including agricultural land, must be converted for the construction of buildings and other infrastructure for the full functioning of renewable energy power plants. The use of vast areas of the countryside for the construction of power plants negatively affects agriculture, fisheries, tourism, and deprives the local population of additional sources of income [35].

Finally, the transition from fossil fuels to renewable energy sources requires a skilled workforce. There is an enormous demand for highly qualified specialists in the design, construction, operation and maintenance of renewable energy power plants. The incompetence of technical specialists and the lack of educational institutions do not allow realizing the potential of renewable energy technologies. It is necessary to conduct courses for specialists in the field of renewable energy to develop the necessary skills. The lack of trained personnel to design, finance, build, operate and maintain renewable energy projects is considered one of the main obstacles to the widespread adoption of renewable energy sources. [25]

In terms of health risks, accidents and diseases are the main sources. This category of risks is becoming especially relevant in light of the unprecedented global health crisis caused by the spread of coronavirus infection. Over the past two decades, technologies in the wind and solar energy sectors have improved significantly, reducing greenhouse gas emissions and creating new industries. The development of renewable energy sources is gaining importance, however, the crisis caused by COVID-19 could disrupt the positive momentum. The impact of the coronavirus crisis on renewable energy can be determined based on the length of the quarantine period and social control measures in different countries, as well as the package of measures to support the economy. Key impacts of the coronavirus crisis on renewable energy could be supply chain disruptions that could delay project completion, fail to take advantage of annual government incentives, and lower investment due to pressures on public and private budgets and uncertainties over electricity demand.

The consequences of coronavirus infection can be illustrated by the example of two scenarios for the development of renewable energy in the Asia-Pacific region (Figure 9). 




Fig. 9. Comparison of the cost of electricity in the Asia-Pacific region depending on the consequences of the COVID-19 -LCOE crisis (\$/MWh) [26]

A study by Wood Mackenzie shows that in 2019 the cost of electricity from renewable energy sources (solar and wind) is lower than the cost of electricity from natural gas, but higher than the cost of electricity from coal.

Next, two scenarios are considered, taking into account the consequences of the pandemic and calculated by 2025. In the first scenario, which is the baseline, there is a decrease in the cost of electricity from renewable energy sources. Consequently, the cost of electricity from renewable sources equaled the cost of electricity from coal, while the price of electricity from natural gas was still high. Finally, the second scenario, called a deep recession, is the low competitiveness of renewable energy sources in relation to coal. So, using the example of the Asia-Pacific region, one can make sure that regardless of the scenario, the cost of electricity from renewable energy sources will be lower than the cost fixed in 2019. However, it is the scenario and severity of the consequences of the pandemic that will determine how much renewable energy can become competitive with coal-fired power plants in this study.

\section{Conclusion}

In conclusion, it should be noted that the fourth energy transition, which consists in increasing the share of renewable energy sources and phasing out fossil fuels, is an integral part of the climate change mitigation strategy. Despite the great potential and positive trend in the development of renewable energy, the study identified the main risks. Tackling these risks should be a priority for both governments and the private sector.

\section{References}

1. Paris Agreement (UN document FCCC/CP/2015/0L.9/Rev.1), https://unfccc.int/

2. Communication from the Commission to the European Parliament, the Council, the European Economic and Social Committee and the Committee of the Regions - The European Green Deal. Brussels, 11.12.2019 COM (2019) 640 final, An official website of the European Union, https://ec.europa.eu/

3. The Lofoten Declaration: Climate Leadership Requires a Managed Decline of Fossil Fuel Production, http://www.lofotendeclaration.org/

4. Forecast for the development of energy in the world and Russia 2019, ed by A. A. Makarov, T. A. Mitrova, V. A. Kulagina, 210 (2019) 
5. M. A. Yulkin, Low-carbon development: from theory to practice, 80 (2018)

6. Accelerating the Energy Transition through Innovation, Web Site REN21, https://www.ren21.net/

7. H. Ahlborg, L. Hammar, Renewable Energy, 61, 117 (2014)

8. I. Hammar, J. Moore, Global Trends in Renewable Energy Investment 2019 (2019)

9. M. F. Ansari, R. K. Kharb, Renewable Sustainable Energy Review, 27, 163 (2016)

10. P. Borawski, A. Beldycka-Borawska, J. of cleaner production, 228, 467 (2019)

11. C. Cho, L. Yang, Renewable Energy, 2, 10 (2013)

12. Climate Emergency, Urban Opportunity. Global report 2019, Coalition for Urban Transitions, https://urbantransitions.global/

13. H. B. Dulal, K. U. Shah, Energy Policy, 59, 301 (2013)

14. Y. V. Fan, Ch. T. Lee, J. of cleaner production, 232, 1482 (2019)

15. N. Gatzert, T. Kosub, Renewable and Sustainable Energy Reviews, 60, 982 (2016)

16. Global Energy Review 2020, Web Site IEA, https://www.iea.org/

17. Global Renewables Outlook: Energy transformation 2050, Abu Dhabi IRENA, https://www.irena.org/

18. V.N. Emodi, S.D. Yusuf, Smart Grid Renewable Energy, 75, 259 (2014)

19. Energy balance guide, Web Site EUROSTAT, https://ec.europa.eu/

20. EU energy in figures Statistical pocketbook 2018, https://publications.europa.eu/

21. M. Hayes, V. Parker, New drivers of the renewable energy transition, https://assets.kpmg/

22. J. Hickel, G. Kallis, New Political Economy (2019) https://static1.squarespace.com/

23. M. Izadbakhsh, M. Gandomkar M., Renewable Energy, 75, 598 (2015)

24. J. Jianjun, D. S. Chen, Energy Policy, 68, 340 (2014)

25. E. Karakaya, P. Sriwannawit, Renewable Sustainable Energy Review, 49, 60 (2015)

26. V. Kretzschmar, Could clean energy be the winner in the oil price war?, Web Site Wood Mackenzie, https://www.woodmac.com

27. Lazard's Levelized Cost of Energy Analysis-Version 13.0, Web Site Lazard, https://www.lazard.com/

28. J. Paravantis , E. Stigka, Renewable Sustainable Energy Review, 32, 100 (2015)

29. Renewables Global Futures Report 2017, Paris REN21 (2018) https://www.ren21.net/

30. Renewables Global Status Report, Paris REN21 (2019) https://www.ren21.net/

31. V. Smil, Energy Transitions: History, Requirements, Prospects, 178 (2010)

32. P. Sun, Nie, Renewable Energy, 74, 255 (2015)

33. The International Energy Charter 2018 Annual Report, 7 March 2019, https://energycharter.org/

34. R Vakulchu, D. Scholtenb, Renewable and Sustainable Energy Reviews, 82, 745 (2020)

35. P. Venkatesh, S.C. Raja, Renewable Sustainable Energy Review, 73, 115 (2017)

36. World Energy Scenarios 2019, https://www.worldenergy.org/

37. H. Zhang, L. Li, Renewable Energy, 63, 330 (2014)

38. A turning point for the hydrocarbon electric power industry, BCS Express, https://bcsexpress.ru/ 
39. W. Mathis, J. Thornhill, Opportunities generated, Bloomberg, https://about.bnef.com/

40. B. Thornhill, The Paradox of Declining Renewable Costs and Rising Electricity Prices, https://www.forbes.com/

41. Our Struggle for Global Sustainability Will Be Won or Lost in Cities, Says SecretaryGeneral, at New York Event, https://www.un.org/

42. Objectifs et fonctionnement de la politique européenne de l'énergie, Synthèse (2017) https://www.touteleurope.eu/ 